Pacific Journal of Mathematics

UPPER AND LOWER BOUNDS FOR EIGENVALUES BY FINITE

J MEs Robe KUTTER 


\title{
UPPER AND LOWER BOUNDS FOR EIGENVALUES BY FINITE DIFFERENCES
}

\section{J. R. KUTTLER}

\begin{abstract}
Upper and lower bounds for the eigenvalues of elliptic partial differential equations associated with fixed membranes and clamped plates are given in terms of corresponding eigenvalues of their finite difference analogues. The upper bounds are found by interpolating piecewise polynomials through the solutions to the difference equations and substituting into the variational principle associated with the differential equations. The lower bounds are found by averaging the solutions to the differential equations and substituting into the discrete variational principle.
\end{abstract}

In this paper we are concerned with the following eigenvalue problems:

the vibration of a fixed membrane,

$$
\Delta u+\lambda u=0 \text { in } R, u=0 \text { on } \partial R \text {; }
$$

the vibration of a clamped plate,

$$
\Delta^{2} v-\Omega v=0 \text { in } R, v=\frac{\partial v}{\partial n}=0 \text { on } \partial R ;
$$

the buckling of a clamped plate,

$$
\Delta^{2} w+\Lambda \Delta w=0 \text { in } R, w=\frac{\partial w}{\partial n}=0 \text { on } \partial R .
$$

Here $R$ is a bounded region of Euclidean $n$-space with boundary $\partial R$, $\Delta$ is the Laplacian, $\partial / \partial n$ the normal derivative.

Each of these problems has a positive sequence of eigenvalues having no finite accumulation point:

$$
0<\lambda^{(1)} \leqq \lambda^{(2)} \leqq \cdots, 0<\Omega^{(1)} \leqq \Omega^{(2)} \leqq \cdots, 0<\Lambda^{(1)} \leqq \Lambda^{(2)} \leqq \cdots .
$$

These eigenvalues may be characterized by the following minimax principles:

$$
\lambda^{(k)}=\min \max _{a_{1}, \cdots, a_{k}} \frac{\sum_{i=1}^{n} \int_{R}\left[\frac{\partial}{\partial x_{i}}\left(a_{1} u_{1}+\cdots+a_{k} u_{k}\right)\right]^{2} d x}{\int_{R}\left[a_{1} u_{1}+\cdots+a_{k} u_{k}\right]^{2}},
$$

where the minimum is over linearly independent sets of functions 
$u_{1}, \cdots, u_{k}$ which are continuous, have piecewise continuous first_derivatives, and have support in $R$;

$$
\begin{gathered}
\Omega^{(k)}=\min \max _{a_{1}, \cdots, a_{k}} \frac{\int_{R}\left[\Delta\left(a_{1} v_{1}+\cdots+a_{k} v_{k}\right)\right]^{2} d x}{\int_{R}\left[a_{1} v_{1}+\cdots+a_{k} v_{k}\right]^{2} d x}, \\
\Lambda^{(k)}=\min \max _{a_{1}, \cdots, a_{k}} \frac{\int_{R}^{n}\left[\Delta\left(a_{1} w_{1}+\cdots+a_{k} w_{k}\right)\right]^{2} d x}{\sum_{i=1}^{n} \int_{R}\left[\frac{\partial}{\partial x_{i}}\left(a_{1} w_{1}+\cdots+a_{k} w_{k}\right)\right]^{2} d x},
\end{gathered}
$$

where the minima are over linearly independent sets of functions $v_{1}, \cdots, v_{k}$ and $w_{1}, \cdots, w_{k}$, respectively, which are continuous, have continuous first derivatives, piecewise continuous second derivatives, and have support in $R$.

We will obtain explicit upper and lower bounds for these eigenvalues in terms of the corresponding eigenvalues of the finite difference analogues:

$$
\begin{aligned}
& \Delta_{h} U+\lambda_{h} U=0 \text { on } R_{h}, U=0 \text { off } R_{h} ; \\
& \Delta_{h}^{2} V-\Omega_{h} V=0 \text { on } R_{h}, V=0 \text { off } R_{h} ; \\
& \Delta_{h}^{2} W+\Lambda_{h} \Delta_{h} W=0 \text { on } R_{h}, W=0 \text { off } R_{h} .
\end{aligned}
$$

Here $R_{h}$ is a bounded subset of the mesh

$$
S_{h} \equiv\left\{\left(i_{1} h, \cdots, i_{n} h\right): i_{1}, \cdots, i_{n} \text { are integers }\right\}
$$

for $h>0$, and $\Delta_{h} \equiv \sum_{i=1}^{n} \partial_{i} \bar{\partial}_{i}$ is the $(2 n+1)$-point approximation of the Laplacian, where $\partial_{i}, \bar{\partial}_{i}$ are forward and backward $i$-th difference operators:

$$
\begin{aligned}
& \partial_{i} U\left(x_{1}, \cdots, x_{n}\right)=h^{-1}\left[U\left(x_{1}, \cdots, x_{i}+h, \cdots, x_{n}\right)-U\left(x_{1}, \cdots, x_{i}, \cdots, x_{n}\right)\right], \\
& \bar{\partial}_{i} U\left(x_{1}, \cdots, x_{n}\right)=h^{-1}\left[U\left(x_{1}, \cdots, x_{i}, \cdots, x_{n}\right)-U\left(x_{1}, \cdots, x_{i}-h, \cdots, x_{n}\right)\right] .
\end{aligned}
$$

Each difference problem has a finite positive sequence of eigenvalues:

$$
\begin{aligned}
0<\lambda_{h}^{(1)} \leqq \lambda_{h}^{(2)} & \leqq \cdots \leqq \lambda_{h}^{(\nu)}, 0<\Omega_{h}^{(1)} \leqq \Omega_{h}^{(2)} \\
& \leqq \cdots \leqq \Omega_{h}^{(\nu)}, 0<\Lambda_{h}^{(1)} \leqq \Lambda_{h}^{(2)} \leqq \cdots \leqq \Lambda_{h}^{(\nu)},
\end{aligned}
$$

where $\nu$ is the number of points in $R_{h}$. These eigenvalues also may be characterized by minimax principles: 


$$
\begin{gathered}
\lambda_{h}^{(k)}=\min \max _{a_{1}, \cdots, a_{k}} \frac{\sum_{i=1}^{n} h^{n} \sum_{S_{h}}\left[\partial_{i}\left(a_{1} U_{1}+\cdots+a_{k} U_{k}\right)\right]^{2}}{h^{n} \sum_{S_{h}}\left[a_{1} U_{1}+\cdots+a_{k} U_{k}\right]^{2}}, \\
\Omega_{h}^{(k)}=\min \max _{a_{1}, \cdots, a_{k}} \frac{h^{n} \sum_{S_{h}}\left[\Delta_{h}\left(a_{1} V_{1}+\cdots+a_{k} V_{k}\right)\right]^{2}}{h^{n} \sum_{S_{h}}\left[a_{1} V_{1}+\cdots+a_{k} V_{k}\right]^{2}}, \\
\Lambda_{h}^{(k)}=\min \max _{a_{1}, \cdots, a_{k}} \frac{h_{i}^{n} \sum_{S_{h}}\left[\Delta_{h}\left(a_{1} W_{1}+\cdots+a_{k} W_{k}\right)\right]^{2}}{h_{h}\left(\partial_{i}\left(a_{1} W_{1}+\cdots+a_{k} W_{k}\right)\right]^{2}},
\end{gathered}
$$

where the minima are over linearly independent sets of mesh functions $U_{1}, \cdots, U_{k}$ and $V_{1}, \cdots, V_{k}$ and $W_{1}, \cdots, W_{k}$, respectively, which vanish off $R_{h}$.

2. The lower bounds. To obtain lower bounds we take the continuous eigenfunctions of problems (1), (2), (3), and average them over cubes of sides $h$ about mesh points. The resulting mesh functions are then admissible candidates for the minimax principles (10), (11), (12). The technique is due to Weinberger [4], who applied it to problems (1) and (3), among others.

To simplify notation, let $x=\left(x_{1}, \cdots, x_{n}\right)$, let $e_{i}$ be the unit vector in the $i$-th coordinate direction, and let

$$
C_{h}(x)=\left\{\left(y_{1}, \cdots, y_{n}\right):\left|y_{i}-x_{i}\right| \leqq \frac{1}{2} h, i=1, \cdots, n\right\}
$$

be the cube of side $h$ about $x$.

If $u$ is a continuous and piecewise differentiable function with support in $R$, then

$$
U(x)=h^{-n} \int_{C_{h}(x)} u(y) d y, \quad x \in S_{h},
$$

is a mesh function which vanishes off $R_{h}$, the subset of $S_{h}$ consisting of points $x$ for which $C_{h}(x) \cap R$ is not empty. Then,

$$
\int_{R} u^{2} d x-h^{n} \sum_{R_{h}} U^{2}=\sum_{x \in R_{h}} \int_{C_{h}(x)}[u(y)-U(x)]^{2} d y
$$

Now since

$$
\int_{C_{h}(x)}[u(y)-U(x)] d y=0
$$

each integral on the right of (14) is bounded by the integral of the square of the gradient of $u$ times the reciprocal of the second free membrane eigenvalue for the cube of side $h$, and 


$$
\int_{R} u^{2} d x-h^{n} \sum_{R_{h} h} U^{2} \leqq \frac{h^{2}}{\pi^{2}} \sum_{i} \int_{R}\left[\frac{\partial u}{\partial x_{i}}\right]^{2} d x
$$

We also have, by integration by parts,

$$
\partial_{i} U(x)=h^{-n-1} \int_{C_{h}\left(x+e_{i} h\right) \cup C_{h}(x)} \psi\left(y_{i}-x_{i}\right) \frac{\partial u(y)}{\partial y_{i}} d y,
$$

where

$$
\psi(\xi)=\left\{\begin{array}{cl}
\xi+\frac{1}{2} h, & -\frac{1}{2} h \leqq \xi \leqq \frac{1}{2} h \\
\frac{3}{2} h-\xi, & \frac{1}{2} h \leqq \xi \leqq \frac{3}{2} h \\
0, & \text { otherwise }
\end{array}\right.
$$

It follows that

$$
\begin{aligned}
& \int_{R}\left[\frac{\partial u}{\partial x_{i}}\right]^{2} d x-h^{n} \sum_{S_{h}}\left[\partial_{i} U\right]^{2} \\
= & h^{-1} \sum_{x \in S_{h}} \int_{C_{h}\left(x+e_{i} h\right) \cup C_{h}(x)} \psi\left(y_{i}-x_{i}\right)\left[\frac{\partial u(y)}{\partial y_{i}}-\partial_{i} U(x)\right]^{2} d y, \\
& i=1, \cdots, n .
\end{aligned}
$$

Therefore, since the right side is positive,

$$
\sum_{i=1}^{n} h^{n} \sum_{S_{h}}\left[\partial_{i} U\right]^{2} \leqq \sum_{i=1}^{n} \int_{R}\left[\frac{\partial u}{\partial x_{i}}\right]^{2} d x
$$

If the function $u$ is continuous, has continuous first derivatives and piecewise continuous second derivatives, each integral on the right side of (17) is bounded by the integral of the square of the gradient of $\partial u / \partial y_{i}$ times the reciprocal of the second eigenvalue $\eta_{2}$ of the weighted free membrane problem

$$
\left\{\begin{array}{cl}
\Delta \varphi(y)+\eta \psi\left(y_{i}-x_{i}\right) \varphi(y)=0, & y \in C_{h}\left(x+e_{i} h\right) \cup C_{h}(x), \\
\frac{\partial \varphi(y)}{\partial n}=0, \quad, & y \in \partial\left[C_{h}\left(x+e_{i} h\right) \cup C_{h}(x)\right] .
\end{array}\right.
$$

The eigenvalue here is the second one because

$$
\int_{C_{h}\left(x+e_{i} h\right) \cup C_{h}(x)} \psi\left(y_{i}-x_{i}\right)\left[\frac{\partial u(y)}{\partial y_{i}}-\partial_{i} U(x)\right] d y=0 .
$$

Since $\psi\left(y_{i}-x_{i}\right) \leqq h$, a lower bound for $\eta_{2}$ is the second eigenvalue of the problem obtained by replacing $\psi$ with $h$ in (19), i.e.,

$$
\eta_{2} \geqq \frac{1}{4} \pi^{2} h^{-3}
$$

Therefore, 
(20)

$$
\sum_{1=i}^{n} h^{n} \sum_{S_{h}}\left[\partial_{i} U\right]^{2} \geqq \sum_{i=1}^{n} \int_{R}\left[\frac{\partial u}{\partial x_{i}}\right]^{2} d x-8 \frac{h^{2}}{\pi^{2}} \int_{R}[\Delta u]^{2} d x .
$$

Still assuming $u$ is continuous, has continuous first derivatives, and piecewise continuous second derivatives, we have, by integration by parts,

$$
\partial_{i} \bar{\partial}_{i} U(x)=h^{-n-2} \int_{C_{h}\left(x-e_{i} h\right) \cup C_{h}(x) \cup C_{h}\left(x+e_{i} h\right)} \widetilde{\psi}\left(y_{i}-x_{i}\right) \frac{\partial^{2} u(y)}{\partial y_{i}^{2}} d y, \quad i=1, \ldots, n,
$$

where

$$
\widetilde{\psi}(\xi)=\left\{\begin{array}{cc}
\frac{1}{2}\left(\xi+\frac{3}{2} h\right)^{2}, & -\frac{3}{2} h \leqq \xi \leqq-\frac{1}{2} h, \\
\frac{3}{4} h^{2}-\xi^{2}, & -\frac{1}{2} h \leqq \xi \leqq \frac{1}{2} h, \\
\frac{1}{2}\left(\xi-\frac{3}{2} h\right)^{2}, & \frac{1}{2} h \leqq \xi \leqq \frac{3}{2} h, \\
0, & \text { otherwise } .
\end{array}\right.
$$

Then

$$
\int_{R}\left[\frac{\partial^{2} u}{\partial x_{i}^{2}}\right]^{2} d x-h^{n} \sum_{S h}\left[\partial_{i} \bar{\partial}_{i} U\right]^{2}
$$

$$
\begin{array}{r}
=h^{-2} \sum_{x \in S_{h}} \int_{C_{h}\left(x-e_{i} h\right) \cup C_{h}(x) \cup C_{h}\left(x+e_{i} h\right)} \tilde{\psi}\left(y_{i}-x_{i}\right)\left[\frac{\partial^{2} u(y)}{\partial y_{i}^{2}}-\partial_{i} \bar{\partial}_{i} U(x)\right]^{2} d y \geqq 0, \\
i=1, \cdots, n .
\end{array}
$$

We also have, for $i \neq j$,

$$
\begin{aligned}
& \int_{R}\left[\frac{\partial^{2} u}{\partial x_{i} \partial x_{j}}\right]^{2} d x-h^{n} \sum_{x \in S h}\left[\partial_{i} \partial_{j} U\right]^{2} \\
= & h^{-2} \sum_{x \in S h} \int_{C_{h}(x) \cup C_{h}\left(x+e_{i} h\right) \cup C_{h}\left(x+e_{j} h\right) \cup C_{h}\left(x+e_{i} h+e_{j} h\right)} \psi\left(y_{i}-x_{i}\right) \Psi\left(y_{j}-x_{j}\right) \\
& \times\left[\frac{\partial^{2} u(y)}{\partial y_{i} \partial y_{j}}-\partial_{i} \partial_{j} U(x)\right]^{2} d y \geqq 0, \quad i, j=1, \ldots, n .
\end{aligned}
$$

Combining (21) and (22), we have

$$
h^{n} \sum_{S_{k}}\left[\Delta_{h} U\right]^{2} \leqq \int_{R}[\Delta u]^{2} d x .
$$

Now we obtain the desired lower bounds. Let $u^{(j)}$ be the eigenfunction associated with $\lambda^{(j)}$ in (1). We may assume

$$
\int_{R} u^{(i)} u^{(j)} d x=\delta(i, j),
$$

where $\delta(i, j)$ is the Kronecker delta. Let

$$
U_{j}(x)=h^{-n} \int_{C_{h}(x)} u^{(j)}(y) d y, \quad x \in R_{h} .
$$


We employ (15) and (18) with $u=a_{1} u^{(1)}+\cdots+a_{k} u^{(k)}, U=a_{1} U_{1}+$ $\cdots+a_{k} U_{k}$ in (10) and see that

$$
\lambda_{h}^{(k)} \leqq \frac{\lambda^{(k)}}{1-\frac{h^{2}}{\pi^{2}} \lambda^{(k)}},
$$

or, what is the same thing,

$$
\frac{\lambda_{h}^{(k)}}{1+\frac{h^{2}}{\pi^{2}} \lambda_{h}^{(k)}} \leqq \lambda^{(k)} .
$$

Next, let $v^{(j)}$ be the eigenfunction associated with $\Omega^{(j)}$ in (2), also such that

$$
\int_{R} v^{(i)} v^{(j)} d x=\delta(i, j)
$$

Let

$$
V_{j}(x)=h^{-n} \int_{C_{h}(x)} v^{(j)}(y) d y, \quad x \in R_{h} .
$$

Employing (15) and (23) with $u=a_{1} v^{(1)}+\cdots+a_{k} v^{(k)}, U=a_{1} V_{1}+$ $\cdots+a_{k} V_{k}$ in (11), we see that

$$
\Omega_{h}^{(k)} \leqq \frac{\Omega^{(k)}}{1-\frac{h^{2}}{\pi^{2}} \Omega^{(k)}},
$$

or, equivalently,

$$
\frac{\Omega_{h}^{(k)}}{1+\frac{h^{2}}{\pi^{2}} \Omega_{h}^{(k)}} \leqq \Omega^{(k)} .
$$

(Inequalities (24) and (25) correspond to (2.25) and (8.10) of [4].) Next, let $w^{(j)}$ be the eigenfunction associated with $\Lambda^{(j)}$ in (3), such that

$$
\sum_{i=1}^{n} \int_{R} \frac{\partial w^{(j)}}{\partial x_{i}} \frac{\partial w^{(l)}}{\partial x_{i}} d x=\delta(j, l)
$$

Let

$$
W_{j}(x)=h^{-n} \int_{C_{h}(x)} w^{(j)}(y) d y,
$$
$x \in R_{h}$.

Employing (20) and (23) with $u=a_{1} w^{(1)}+\cdots+a_{k} w^{(k)}, U=a_{1} W_{1}+$ $\cdots+a_{k} W_{k}$ in (12), we see that 


$$
\Lambda_{h}^{(k)} \leqq \frac{\Lambda^{(k)}}{1-8 \frac{h^{2}}{\pi^{2}} \Lambda^{(k)}},
$$

or,

$$
\frac{\Lambda_{h}^{(k)}}{1+8 \frac{h^{2}}{\pi^{2}} \Lambda_{h}^{(k)}} \leqq \Lambda^{(k)}
$$

This inequality is new.

3. The upper bounds. To obtain upper bounds we take the mesh eigenfunctions of problems (7), (8), (9) and interpolate to obtain admissible candidates for the minimax problems (4), (5), (6).

Pólya [3] has applied this technique to problem (1) using piecewise linear interpolation. Specifically, he considered the mesh domain $R_{h}$ consisting of points $x$ in $S_{h}$ such that $C_{2 h}(x) \subset R$. Each mesh square with vertices at points of $S_{h}$ he divided into two triangles by a diagonal through two vertices. Given a mesh function $U$ which vanishes off $R_{h}$, he interpolated a function $u$, linear on each triangle and agreeing with $U$ at the vertices. He then proved the estimates

$$
\begin{gathered}
\int_{R} u^{2} d x \geqq h^{2} \sum_{x \in R_{h}} U^{2}-\frac{1}{4} h^{2} \sum_{i=1}^{2} h^{2} \sum_{x \in R_{h}}\left[\partial_{i} U\right]^{2}, \\
\sum_{i=1}^{2} \int_{R}\left[\frac{\partial u}{\partial v_{i}}\right]^{2} d x=\sum_{i=1}^{2} h^{2} \sum_{x \in S_{h}}\left[\partial_{i} U\right]^{2},
\end{gathered}
$$

from which it follows that, for $n=2$,

$$
\lambda^{(k)} \leqq \frac{\lambda_{h}^{(k)}}{1-\frac{1}{4} h^{2} \lambda_{h}^{(k)}} .
$$

Weinberger [4] indicates how this may be extended to higher dimensions.

For the problems (2) and (3), however, piecewise linear functions are not smooth enough to be admissible in (5) and (6). We must interpolate with functions which are cubic polynomials in each space variable in each mesh cube, and such that the function is continuous with continuous first derivatives across the sides of the cube.

Let us first consider the one-dimensional case $(n=1)$. Given a mesh function $U$, we uniquely define the interpolating function, $P_{h} U$, by requiring that for $x \in S_{h}$

$$
P_{h} U(x)=U(x), \frac{d}{d x}\left[P_{h} U(x)\right]=\frac{1}{2}[\partial U(x)+\bar{\partial} U(x)] .
$$

By linearity, 


$$
P_{h} U(x)=\sum_{y \in S_{h}} U(y) P_{h} \delta(x, y),
$$

so it suffices to define

$$
\begin{aligned}
& k_{h}(x-y) \equiv P_{h} \delta(x, y) \\
= & \left\{\begin{array}{cl}
1-\frac{5}{2}\left|\frac{x-y}{h}\right|^{2}+\frac{3}{2}\left|\frac{x-y}{h}\right|^{3} & ,|x-y| \leqq h, \\
2-4\left|\frac{x-y}{h}\right|+\frac{5}{2}\left|\frac{x-y}{h}\right|^{2}-\frac{1}{2}\left|\frac{x-y}{h}\right|^{3}, & h \leqq|x-y| \leqq 2 h, \\
0 & , 2 h \leqq|x-y| .
\end{array}\right.
\end{aligned}
$$

For general $n$, then, we define

$$
\begin{aligned}
P_{h} U(x) & =P_{h, x_{1}} P_{h, x_{2}} \cdots P_{h, x_{n}} U\left(x_{1}, \cdots, x_{n}\right) \\
& =\sum_{y \in R_{h}} U(y) \prod_{i=1}^{n} k_{h}\left(x_{i}-y_{i}\right) .
\end{aligned}
$$

Let us assume $R_{h}$ consists of point $x$ of $R_{h}$ such that $C_{4 h}(x) \subset R$. Then, for $U$ vanishing off $R_{h}, P_{h} U$ will vanish off $R$. We now wish to estimate

$$
\int_{R}\left[P_{h} U\right]^{2} d x
$$

Let us again first do the case $n=1$. We have

$$
\begin{aligned}
\int_{-\infty}^{\infty}\left[P_{h} U\right]^{2} d z= & \sum_{x, y \in S h} U(x) U(y) \int_{-\infty}^{+\infty} k_{h}(x-z) k_{h}(y-z) d z \\
= & \sum_{x, y \in S_{h}} U(x) U(y) \int_{-\infty}^{+\infty} k_{h}(z) k_{h}(z+x-y) d z \\
= & \sum_{x \in S_{h}} U(x)\left\{U(x) \int_{-\infty}^{+\infty}\left[k_{h}(z)\right]^{2} d z+[U(x-h)+U(x+h)]\right. \\
& \times \int_{-\infty}^{+\infty} k_{h}(z) k_{h}(z+h) d z+[U(x-2 h)+U(x+2 h)] \\
& \times \int_{-\infty}^{+\infty} k_{h}(z) k_{h}(z+2 h) d z+[U(x-3 h)+U(x+3 h)] \\
& \left.\times \int_{-\infty}^{+\infty} k(z) k(z+3 h) d z\right\} \\
= & h \sum_{x \in S_{h}} U(x)\left\{\frac{57}{70} U(x)+\frac{71}{560}[U(x-h)+U(x+h)]\right. \\
& -\frac{1}{28}[U(x-2 h)+U(x+2 h)] \\
& \left.+\frac{1}{560}[U(x-3 h)+U(x+3 h)]\right\} \\
= & h \sum_{x \in S_{h}} U(x)\left\{I-\frac{1}{40} h^{4} \partial^{2} \bar{\partial}^{2}+\frac{1}{560} h^{6} \partial^{3} \bar{\partial}^{3}\right\} U(x) .
\end{aligned}
$$


Then, for general $n$, we have

$$
\begin{aligned}
\int_{R}\left[P_{h} U\right]^{2} d z & =\sum_{x, y \in S_{h}} U(x) U(y) \prod_{i=1}^{n} \int_{-\infty}^{+\infty} k_{h}\left(x_{i}-z_{i}\right) k_{h}\left(y_{i}-z_{i}\right) d z_{i} \\
& =h^{n} \sum_{x \in S_{h}} U(x) \prod_{i=1}^{n}\left[I-\frac{1}{40} h^{4} \partial_{i}^{2} \bar{\partial}_{i}^{2}+\frac{1}{560} h^{6} \partial_{i}^{3} \bar{\partial}_{i}^{3}\right] U(x) .
\end{aligned}
$$

Similarly, we have

(29)

$$
\begin{aligned}
\sum_{i=1}^{n} \int_{R}\left[\frac{\partial}{\partial z_{i}} P_{h} U\right]^{2} d z= & \sum_{i=1}^{n} \sum_{x, y \in S_{h}} U(x) U(y) \int_{-\infty}^{+\infty} k_{h}^{\prime}\left(x_{i}-z_{i}\right) k_{h}^{\prime}\left(y_{i}-z_{i}\right) d z \\
& \times \prod_{\substack{j=1 \\
j \neq i}}^{n} \int_{-\infty}^{+\infty} k_{h}\left(x_{j}-z_{j}\right) k_{h}\left(y_{j}-z_{j}\right) d z \\
= & -\sum_{i=1}^{n} h^{n} \sum_{x \in S_{h}} U(x)\left[\partial_{i} \bar{\partial}_{i}-\frac{1}{12} h^{2} \partial_{i}^{2} \bar{\partial}_{i}^{2}-\frac{1}{120} h^{4} \partial_{2}^{3} \bar{\partial}_{i}^{3}\right] \\
& \times \prod_{\substack{j=1 \\
j \neq i}}^{n}\left[I-\frac{1}{40} h^{4} \partial_{j}^{2} \bar{\partial}_{j}^{2}+\frac{1}{560} h^{6} \partial_{j}^{3} \bar{\partial}_{j}^{3}\right] U(x) .
\end{aligned}
$$

Also,

$(30)$

$$
\begin{aligned}
\int_{R}\left[\Delta P_{h} U\right]^{2} d z= & \sum_{x, y \in S_{h}} U(x) U(y)\left[\sum_{i=1}^{n} \int_{-\infty}^{+\infty} k_{h}^{\prime \prime}\left(x_{i}-z_{i}\right) k^{\prime \prime}\left(y_{i}-z_{i}\right) d z\right. \\
& \times \prod_{\substack{j=1 \\
j \neq i}}^{n} \int_{-\infty}^{+\infty} k_{h}\left(x_{j}-z_{j}\right) k_{h}\left(y_{j}-z_{j}\right) d z_{j} \\
& +\sum_{\substack{i, j=1 \\
i \neq j}}^{n} \int_{-\infty}^{+\infty} k_{h}^{\prime}\left(x_{i}-z_{i}\right) k_{h}^{\prime}\left(y_{i}-z_{i}\right) d z_{i} \\
& \times \int_{-\infty}^{+\infty} k_{h}^{\prime}\left(x_{j}-z_{j}\right) k_{h}^{\prime}\left(y_{j}-z_{j}\right) d z_{j} \\
& \left.\times \prod_{\substack{l=1 \\
l \neq i, j}}^{n} \int_{-\infty}^{+\infty} k_{h}\left(x_{l}-z_{l}\right) k_{h}\left(y_{l}-z_{l}\right) d z_{l}\right] \\
= & h^{n} \sum_{\substack{x \in S_{h} \\
\text { ind }}} U(x)\left\{\sum_{i=1}^{n}\left[\partial_{i}^{2} \bar{\partial}_{i}^{2}-\frac{1}{2} h^{2} \partial_{i}^{3} \bar{\partial}_{i}^{3}\right]\right. \\
& \times \prod_{\substack{j=1 \\
j \neq i}}^{n}\left[I-\frac{1}{40} h^{4} \partial_{j}^{2} \bar{\partial}_{j}^{2}+\frac{1}{560} h^{6} \partial_{j}^{3} \bar{\partial}_{j}^{3}\right] \\
& +\sum_{\substack{i, j=1 \\
i \neq j}}^{n}\left[\partial_{i} \bar{\partial}_{i}-\frac{1}{12} h^{2} \partial_{i}^{2} \bar{\partial}_{i}^{2}-\frac{1}{120} h^{4} \partial_{i}^{3} \bar{\partial}_{i}^{3}\right] \\
& \times\left[\partial_{j} \bar{\partial}_{j}-\frac{1}{12} h^{2} \partial_{j}^{2} \bar{\partial}_{j}^{2}-\frac{1}{120} h^{4} \partial_{j}^{3} \bar{\partial}_{j}^{3}\right] \\
& \left.\times \prod_{\substack{l=1 \\
l \neq i, j}}^{n}\left[I-\frac{1}{40} h^{4} \partial_{l}^{2} \bar{\partial}_{l}^{2}+\frac{1}{560} h^{6} \partial_{l}^{3} \bar{\partial}_{l}^{3}\right]\right\} U(x)
\end{aligned}
$$

The desired inequalities are obtained from (28), (29), (30) by using the summation by parts formula 


$$
\sum_{S_{h}} U \bar{\partial}_{i} V=-\sum_{S_{h}} V \partial_{i} U,
$$

for functions with compact support. We consider the case $n=2$. From (28) we have

$$
\begin{aligned}
\int_{R}\left[P_{h} U\right]^{2} d x= & h^{2} \sum_{S_{h}}\left\{U^{2}-\frac{1}{40} h^{4}\left(\left[\partial_{1}^{2} U\right]^{2}+\left[\partial_{2}^{2} U\right]^{2}\right)\right. \\
& -\frac{1}{560} h^{6}\left(\left[\partial_{1}^{3} U\right]^{2}+\left[\partial_{2}^{3} U\right]^{2}\right)+\frac{1}{1600} h^{8}\left[\partial_{1}^{2} \partial_{2}^{2} U\right]^{2} \\
& \left.+\frac{1}{22400} h^{10}\left(\left[\partial_{1}^{2} \partial_{2}^{3} U\right]^{2}+\left[\partial_{1}^{3} \partial_{2} U\right]^{2}\right)+\frac{1}{313600} h^{12}\left[\partial_{1}^{3} \partial_{2}^{3} U\right]^{2}\right\} \\
\geqq & h^{2} \sum_{S_{h}}\left\{U^{2}-\frac{1}{40} h^{4}\left(\left[\partial_{1}^{2} U\right]^{2}+2\left[\partial_{1} \partial_{2} U\right]^{2}+\left[\partial_{2} U\right]^{2}\right)\right. \\
& \left.-\frac{1}{560} h^{6}\left(\left[\partial_{1}^{3} U\right]^{2}+3\left[\partial_{1}^{2} \partial_{2} U\right]^{2}+3\left[\partial_{1} \partial_{2}^{2} U\right]^{2}+\left[\partial_{2}^{3} U\right]^{2}\right)\right\} .
\end{aligned}
$$

Therefore,

$$
\int_{R}\left[P_{h} U\right]^{2} d x \geqq h^{2} \sum_{S_{h}} U\left[U-\frac{1}{40} h^{2} \Delta_{h}^{2} U+\frac{1}{560} h^{6} \Delta_{h}^{3} U\right] .
$$

Similarly, from (29), we have

$$
\begin{aligned}
\sum_{i=1}^{2} \int_{R}\left[\frac{\partial}{\partial x_{i}} P_{h} U\right]^{2} d x \geqq h^{2} \sum_{S_{h}} U & {\left[-\Delta_{h} U+\frac{1}{120} h^{4} \Delta_{h}^{3} U-\frac{1}{2240} h^{6} \Delta_{h}^{4} U\right], } \\
\sum_{i=1}^{2} \int_{R}\left[\frac{\partial}{\partial x_{i}} P_{h} U(x)\right]^{2} d x \leqq h^{2} \sum_{S_{h}} U & {\left[-\Delta_{h} U+\frac{1}{12} h^{2} \Delta_{h}^{2} U\right.} \\
& \left.-\frac{1}{168000} h^{8} \Delta_{h}^{5} U+\frac{1}{1334000} h^{10} \Delta_{h}^{6} U\right],
\end{aligned}
$$

and from (30), we have

$$
\int_{R}\left[\Delta P_{h} U\right]^{2} d x \leqq h^{2} \sum_{S_{h}} U\left[\Delta_{h}^{2} U-\frac{1}{2} h^{2} \Delta_{h}^{3} U\right] .
$$

Now we obtain the upper bounds. Let $U_{h}^{(j)}$ be the eigenfunction associated with $\lambda_{h}^{(j)}$ in (7) such that

$$
h^{n} \sum_{S_{h}} U_{h}^{(i)} U_{h}^{(j)}=\delta(i, j) .
$$

Let $u_{j}=P_{h} U_{h}^{(j)}$. We use (31) and (33) in (4) with $U=a_{1} U_{h}^{(1)}+\cdots$ $+a_{k} U_{k}^{(k)}$ to see that, for $n=2$,

$$
\lambda^{(k)} \leqq \frac{\lambda_{h}^{(k)}+\frac{1}{12} h^{2} \lambda_{h}^{(k)^{2}}+\frac{1}{168000} h^{8} \lambda_{h}^{(k) 5}+\frac{1}{1334000} h^{10} \lambda_{h}^{(k) 6}}{1-\frac{1}{40} h^{4} \lambda_{h}^{(k)^{2}}-\frac{1}{560} h^{6} \lambda_{h}^{(k) 3}}
$$




$$
=\lambda_{h}^{(k)}+\frac{1}{12} h^{2} \lambda^{(k)^{2}}+0\left(h^{4} \lambda_{h}^{(k)^{3}}\right),
$$

which, for $h$ sufficiently small, is a better bound than (27). Let $V_{h}^{(j)}$ be the eigenfunction associated with $\Omega_{h}^{(j)}$ in (8) such that

$$
h^{n} \sum_{S_{h}} V_{h}^{(i)} V_{h}^{(j)}=\delta(i, j) \text {. }
$$

Let $v_{j}=P_{h} V_{h}^{(j)}$. Use (31) and (34) in (5) with $U=a_{1} V_{h}^{(1)}+\cdots+$ $a_{k} V_{h}^{(k)}$ to see that, for $n=2$,

$$
\Omega^{(k)} \leqq \frac{\Omega_{h}^{(k)}+\frac{1}{2} h^{2} \Omega_{h}^{(k) 3 / 2}}{1-\frac{1}{40} h^{4} \Omega_{h}^{(k)}-\frac{1}{560} h^{6} \Omega_{h}^{(k) 3 / 2}}
$$

(where the Schwarz inequality was employed).

Finally, let $W_{h}^{(j)}$ be the eigenfunction associated with $\Lambda_{h}^{(j)}$ in (9) such that

$$
\sum_{i=1}^{n} h^{n} \sum_{S_{h}} \partial_{i} W_{h}^{(j)} \partial_{i} W_{h}^{(l)}=\delta(j, l) \text {. }
$$

Let $w_{j}=P_{h} W_{h}^{(j)}$. Use (32) and (34) in (6) with $U=a_{1} W_{h}^{(1)}+\cdots+$ $a_{k} W_{h}^{(k)}$ to see that, for $n=2$,

$$
\Lambda^{(k)} \leqq \frac{\Lambda_{h}^{(k)}+\frac{1}{2} h^{2} \Lambda_{h}^{(k)^{2}}}{1-\frac{1}{120} h^{4} \Lambda_{h}^{(k) 2}-\frac{1}{2240} h^{6} \Lambda_{h}^{(k)^{3}}} .
$$

Explicit upper bounds for higher dimensions may be obtained in the same fashion from (28), (29), and (30). It is clear that, in general,

$$
\begin{aligned}
\lambda^{(k)} & \leqq \lambda_{h}^{(k)}+0\left(h^{2} \lambda_{h}^{(k) 2}\right), \\
\Omega^{(k)} & \leqq \Omega_{h}^{(k)}+0\left(h^{2} \Omega_{h}^{(k) 3 / 2}\right), \\
\Lambda^{(k)} & \leqq \Lambda_{h}^{(k)}+0\left(h^{2} \Lambda_{h}^{(k)^{2}}\right) .
\end{aligned}
$$

4. Conclusion. We notice that the lower bounds (24), (25), (26) are in terms of difference problems on an $R_{h}$ such that

$$
R \subset \bigcup_{x \in R h} C_{h}(x),
$$

while the upper bounds (38), (39), (40) are in terms of difference problems on an $R_{h}$ such that

$$
\bigcup_{x \in R_{h}} C_{4 h}(x) \subset R .
$$

However, the problems (1), (2), (3) depend continuously on the domain 
$R$ in such a way that if $R, R^{\prime}$ are domains whose boundaries are within $0(h)$, then, for each $k$, the eigenvalues $\lambda^{(k)}, \Omega^{(k)}, \Lambda^{(k)}$ for $R$ are within $0(h)$ of the eigenvalues $\lambda^{\prime(k)}, \Omega^{\prime(k)}, \Lambda^{\prime(k)}$ for $R^{\prime}$, respectively. With this consideration, we can combine the bounds (24) and (38), (25) and (39), (26) and (40), to say that if $R_{h}$ is such that $\mathrm{U}_{x \in R_{h}} C_{h}(x)$ has boundary within $O(h)$ of the boundary of $R$, then

$$
\begin{aligned}
& \left|\lambda^{(k)}-\lambda_{h}^{(k)}\right|=O(h), \\
& \left|\Omega^{(k)}-\Omega_{h}^{(k)}\right|=O(h), \\
& \left|\Lambda^{(k)}-\Lambda_{h}^{(k)}\right|=O(h) .
\end{aligned}
$$

Estimates like (41), (42), (43) can be used in proving convergence of more accurate finite difference schemes which may be regarded as perturbations of the schemes (7), (8), (9). See the paper [2] for details.

Upper and lower bounds for eigenvalues of free membranes by similar techniques may be found in [1]. Further references may be found in [1], [2] and [4].

\section{REFERENCES}

1. B. E. Hubbard, Bounds for eigenvalues of the free and fixed membrane by finite difference methods, Pacific J. Math. 11 (1961), 559-590.

2. J. R. Kuttler, Finite difference approximations for eigenvalues of uniformly elliptic operators, SIAM J. Numer. Analysis, 7 (1970), 206-232.

3. G. Pólya, Sur une interprétation de la méthode des differences finies qui peur fournir des bornes supérieures ou inférieures, C. R. Acad. Sci. Paris 235 (1952), 995997.

4. H. F. Weinberger, Lower bounds for higher eigenvalues by finite difference methods, Pacific J. Math. 8 (1958), 339-368,

Received June 19, 1969. This work supported by the Department of the Navy, Bureau of Naval Weapons, under Contract NOw 62-0604-c.

The Johns Hopkins University

APPlied Physics Laboratory 


\section{PACIFIC JOURNAL OF MATHEMATICS}

\section{EDITORS}

\author{
H. SAMELSON \\ Stanford University \\ Stanford, California 94305

\section{Richard Pierce} \\ University of Washington \\ Seattle, Washington 98105
}

J. DugundJI

Department of Mathematics

University of Southern California

Los Angeles, California 90007

RichaRd ARENS

University of California

Los Angeles, California 90024

\section{ASSOCIATE EDITORS}
E. F. BECKENBACH
B. H. NeUMANN
F. WOLE
K. YoshidA

\section{SUPPORTING INSTITUTIONS}

\author{
UNIVERSITY OF BRITISH COLUMBIA \\ CALIFORNIA INSTITUTE OF TECHNOLOGY \\ UNIVERSITY OF CALIFORNIA \\ MONTANA STATE UNIVERSITY \\ UNIVERSITY OF NEVADA \\ NEW MEXICO STATE UNIVERSITY \\ OREGON STATE UNIVERSITY \\ UNIVERSITY OF OREGON \\ OSAKA UNIVERSITY \\ UNIVERSITY OF SOUTHERN CALIFORNIA
}

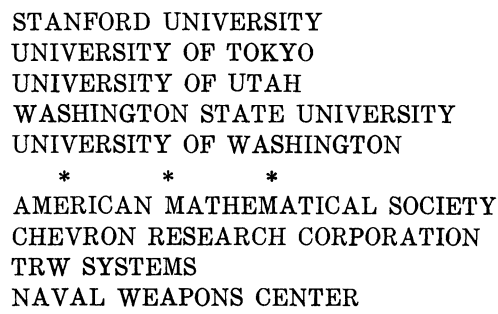

The Supporting Institutions listed above contribute to the cost of publication of this Journal, but they are not owners or publishers and have no responsibility for its content or policies.

Mathematical papers intended for publication in the Pacific Journal of Mathematics should be in typed form or offset-reproduced, (not dittoed), double spaced with large margins. Underline Greek letters in red, German in green, and script in blue. The first paragraph or two must be capable of being used separately as a synopsis of the entire paper. The editorial "we" must not be used in the synopsis, and items of the bibliography should not be cited there unless absolutely necessary, in which case they must be identified by author and Journal, rather than by item number. Manuscripts, in duplicate if possible, may be sent to any one of the four editors. Please classify according to the scheme of Math. Rev. Index to Vol. 39. All other communications to the editors should be addressed to the managing editor, Richard Arens, University of California, Los Angeles, California, 90024.

50 reprints are provided free for each article; additional copies may be obtained at cost in multiples of 50 .

The Pacific Journal of Mathematics is published monthly. Effective with Volume 16 the price per volume (3 numbers) is $\$ 8.00$; single issues, $\$ 3.00$. Special price for current issues to individual faculty members of supporting institutions and to individual members of the American Mathematical Society: $\$ 4.00$ per volume; single issues $\$ 1.50$. Back numbers are available.

Subscriptions, orders for back numbers, and changes of address should be sent to Pacific Journal of Mathematics, 103 Highland Boulevard, Berkeley, California, 94708.

PUBLISHED BY PACIFIC JOURNAL OF MATHEMATICS, A NON-PROFIT CORPORATION

Printed at Kokusai Bunken Insatsusha (International Academic Printing Co., Ltd.), 7-17, Fuj̣imi 2-chome, Chiyoda-ku, Tokyo, Japan. 


\section{Pacific Journal of Mathematics}

\section{Vol. 35, No. $2 \quad$ October, 1970}

Valentin Danilovich Belousov and Palaniappan L. Kannappan, Generalized Bol functional equation .................................... 259

Charles Morgan Biles, Gelfand and Wallman-type compactifications ........... 267

Louis Harvey Blake, A generalization of martingales and two consequent convergence theorems .................................... 279

Dennis K. Burke, On p-spaces and $w \Delta$-spaces..................... 285

John Ben Butler, Jr., Almost smooth perturbations of self-adjoint operators . . . . . . 297

Michael James Cambern, Isomorphisms of $C_{0}(Y)$ onto $C(X) \ldots \ldots \ldots \ldots \ldots . \ldots 307$

David Edwin Cook, A conditionally compact point set with noncompact closure ... 313

Timothy Edwin Cramer, Countable Boolean algebras as subalgebras and homomorphs .........................................

John R. Edwards and Stanley G. Wayment, A v-integral representation for linear operators on spaces of continuous functions with values in topological vector spaces.............................................

Mary Rodriguez Embry, Similarities involving normal operators on Hilbert

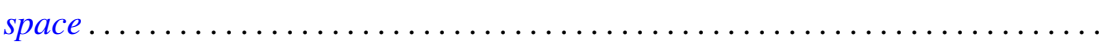

Lynn Harry Erbe, Oscillation theorems for second order linear differential

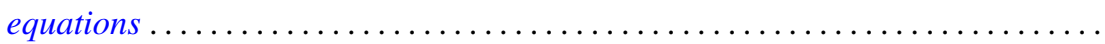

William James Firey, Local behaviour of area functions of convex bodies .......... Joe Wayne Fisher, The primary decomposition theory for modules ..............

Gerald Seymour Garfinkel, Generic splitting algebras for Pic ..................

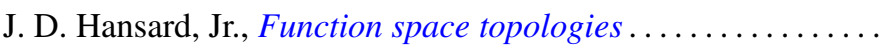

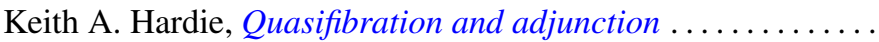

G. Hochschild, Coverings of pro-affine algebraic groups ...........

Gerald L. Itzkowitz, On nets of contractive maps in uniform spaces ..

381

389

399

417

Melven Robert Krom and Myren Laurance Krom, Groups with free nonabelian subgroups....................................

James Robert Kuttler, Upper and lower bounds for eigenvalues by finite differences ......................................

Dany Leviatan, A new approach to representation theory for convolution transforms . . .

Richard Beech Mansfield, Perfect subsets of definable sets of real numbers ...

Brenda MacGibbon, A necessary and sufficient condition for the embedding of a

Lindelof space in a Hausdorff $\mathscr{H} \sigma$ space ..................

David G. Mead and B. D. McLemore, Ritt's question on the Wronskian ....

Edward Yoshio Mikami, Focal points in a control problem .....

Paul G. Miller, Characterizing the distributions of three independent n-dimensional random variables, $X_{1}, X_{2}, X_{3}$, having analytic characteristic functions by the joint distribution of $\left(X_{1}+X_{3}, X_{2}+X_{3}\right)$. . .

P. Rosenthal, On the Bergman integral operator for an elliptic partial differential equation with a singular coefficient....

Douglas B. Smith, On the number of finitely generated $O$-group 